\title{
AVALIAÇÃO DO PROCESSO DE RECOBRIMENTO DE UREIA EM LEITO DE JORRO: MORFOLOGIA DAS PARTÍCULAS E VOLATILIDADE DO NITROGÊNIO
}

\author{
F. B. DALLA NORA ${ }^{1}$, B. DE ZORZI ${ }^{1}$, G. F. WESTPHALEN ${ }^{1}$, T. PACHECO ${ }^{1}$ e G. S. \\ ROSA $^{1}$ \\ ${ }^{1}$ Universidade Federal do Pampa, Curso de Engenharia Química \\ E-mail para contato: fabiolabalzan@gmail.com
}

\begin{abstract}
RESUMO - O uso dos fertilizantes nitrogenados é essencial na agricultura, sendo a ureia o produto nitrogenado que mais possui destaque. No entanto, a quantidade de nitrogênio perdido por volatilização, após a aplicação de ureia sobre a superfície do solo pode atingir valores extremos de até $78 \%$ do nitrogênio aplicado. Neste sentido, para que haja a diminuição dessa rápida volatilização é feito o recobrimento das partículas de ureia. Este trabalho teve como objetivo avaliar o impacto do processo de recobrimento da ureia em leito de jorro na morfologia das partículas e na volatilidade do nitrogênio. Verificou-se através desse estudo que a película de recobrimento proporcionou uma diminuição das perdas por volatilização de nitrogênio para todas as condições do estudo, em que o percentual de redução na volatilidade ficou entre de 17 e $50 \%$. Também foi verificado que o recobrimento que mais reduziu a volatilização foi o ensaio com temperatura do ar de $85{ }^{\circ} \mathrm{C}$ e vazão de suspensão de $15 \mathrm{~mL} / \mathrm{min}$. Através das microscopias observou-se que os recobrimentos com maiores vazões de suspensão formaram nas partículas um filme mais uniforme e homogêneo.
\end{abstract}

\section{INTRODUÇÃO}

A ureia é o fertilizante sólido granulado mais utilizado na agricultura brasileira, pois possui uma grande quantidade de nitrogênio em sua composição, aproximadamente $45 \%$. Como vantagem da utilização deste fertilizante nitrogenado, tem-se o baixo custo de transporte, alta solubilidade, baixa corrosividade e facilidade de mistura com outras fontes (Duarte et al.,2007; Rosa, 2009). Como desvantagem, possui elevada higrocospicidade e susceptibilidade à volatilização do nitrogênio (Padilha et al., 2005; Rosa, 2009).

A quantidade de $\mathrm{N}_{-} \mathrm{NH}_{3}$ perdida por volatilização, após a aplicação de ureia sobre a superfície do solo pode atingir valores extremos de até $78 \%$ do nitrogênio aplicado (Lara Cabezas et al., 1997). O recobrimento é feito com o objetivo de diminuir essa rápida volatilização do nitrogênio. Assim, ele será liberado lentamente, obedecendo às necessidades da planta. Outro objetivo do recobrimento é diminuir a higroscopicidade da partícula, aumentando assim a sua eficiência.

O estudo do recobrimento de ureia tem sido realizado por diversos pesquisadores, através de diferentes técnicas (tambor rotatório, leito fluidizado, leito de jorro) e diferentes materiais (enxofre, resinas e polímeros). Nesse sentido, o objetivo deste trabalho foi avaliar o 

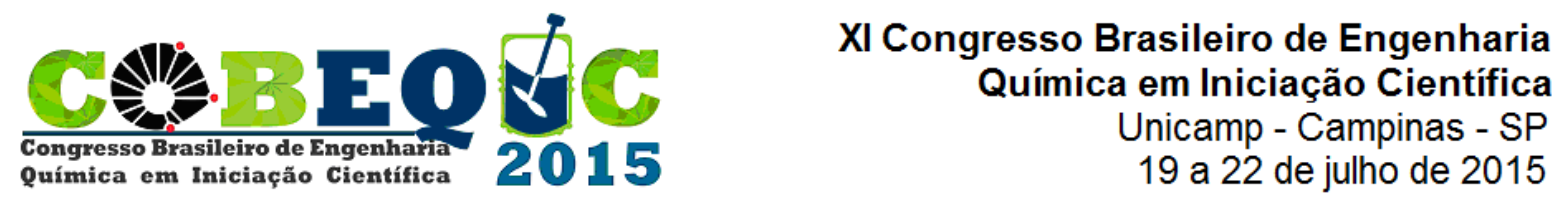

impacto do processo de recobrimento de ureia em leito de jorro na morfologia das partículas e na redução da volatilidade do nitrogênio.

\section{MATERIAIS E MÉTODOS}

Para o recobrimento da ureia foi utilizada uma suspensão aquosa de natureza polimérica capaz de fornecer uma superfície de recobrimento uniforme e de baixo custo. Para isso, foram realizados testes com o objetivo de formular uma suspensão que proporcione formação de filme liso e uniforme, e com adequada concentração de sólidos, visando obter espessura de filme suficiente, a fim de minimizar as perdas de nitrogênio por volatilização. A formulação da suspensão aquosa escolhida apresenta em peso: $0,5 \%$ de gelatina, $0,5 \%$ de amido, $2 \%$ do polímero comercial ColorSeed $\AA$, $3 \%$ de plastificante (glicerol), $9 \%$ de talco e $85 \%$ de água.

Por seguinte, foram realizados os ensaios de recobrimento com essa suspensão no leito de jorro, mostrado na Figura 1.

Figura 1 - Leito de Jorro.

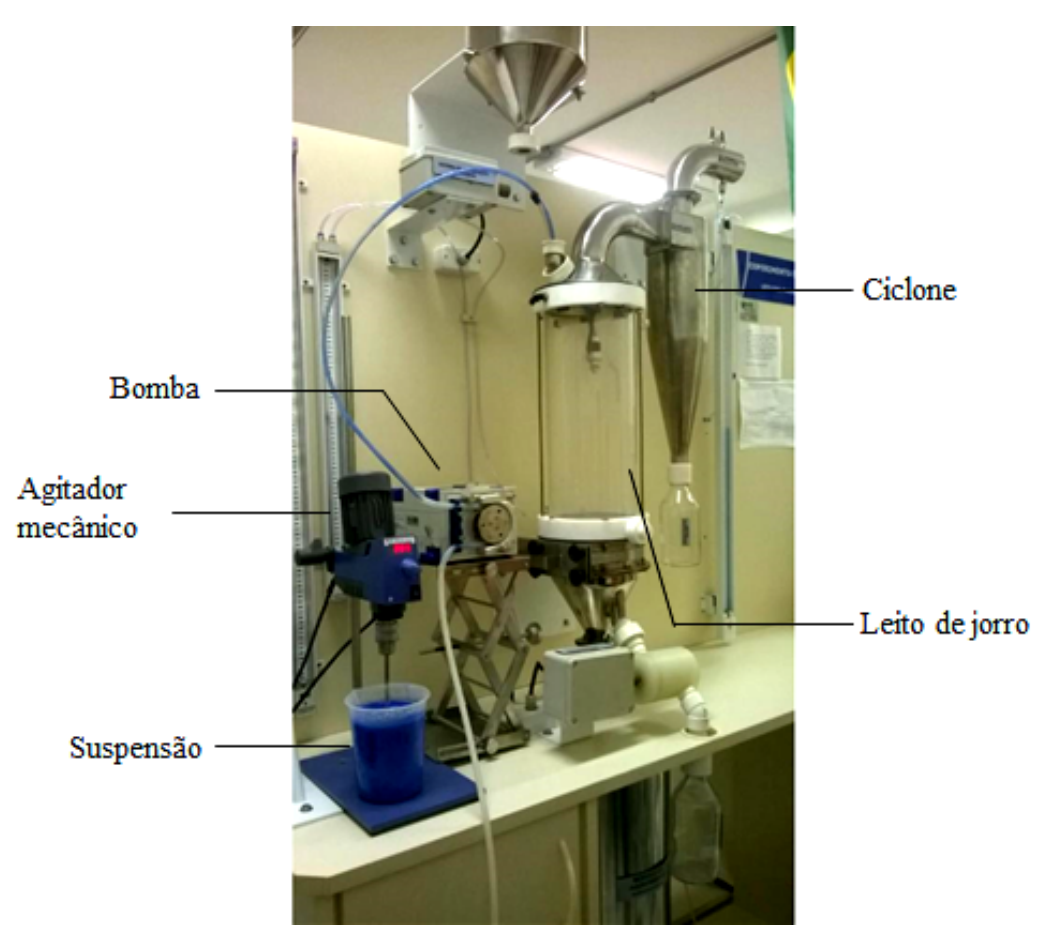

Os experimentos de recobrimento consistiram em abastecer o leito de jorro com a carga de ureia de $500 \mathrm{~g}$ e em seguida foi iniciada a alimentação do ar de jorro através do soprador, sendo que este ar foi aquecido através de passagem em um conjunto de resistências. A vazão do ar foi ajustada no painel de controle e medida pela placa de orifício. Quando a temperatura de entrada do ar atingiu o valor desejado foi iniciada a alimentação da suspensão de recobrimento por meio de uma bomba peristáltica na vazão de atomização estabelecida. 
A suspensão foi atomizada através de um bico atomizador de duplo fluido, localizado na parte superior do leito, onde vazão do ar de atomização era fornecida por um compressor com $0,5 \mathrm{kgf} / \mathrm{cm}^{2}$. O tempo de atomização da suspensão foi fixado em 20 min para todos os experimentos.

Foram realizados 4 ensaios de recobrimento a fim de analisar a influência das condições operacionais na redução da volatilidade da ureia. As diferentes condições utilizadas de temperatura do ar de jorro $\left(\mathrm{T}_{\mathrm{ar}}\right)$ e vazão da suspensão de recobrimento $\left(\mathrm{Q}_{\text {susp }}\right)$ estão apresentadas na Tabela 1.

Tabela 1 - Condições dos ensaios de recobrimento.

\begin{tabular}{rcc}
\hline Ensaio & $\mathrm{T}_{\mathrm{ar}}\left({ }^{\circ} \mathrm{C}\right)$ & $\mathrm{Q}_{\text {susp }}(\mathrm{mL} / \mathrm{min})$ \\
\hline 1 & 65 & 9 \\
2 & 65 & 15 \\
3 & 85 & 9 \\
4 & 85 & 15 \\
\hline
\end{tabular}

Foram realizadas as análises da volatilidade do nitrogênio contido na ureia quando esta é aplicada no solo, antes e após o recobrimento, possibilitando realizar uma análise comparativa entre as amostras. O nitrogênio volatilizado foi quantificado na forma de amônia pelo método direto com sistema de captação estático (Duarte, 2007). A câmara de volatilização consistiu em um frasco de plástico cilíndrico dotado de tampa. Nos frascos foram colocados $100 \mathrm{~g}$ de terra, onde a ureia foi distribuída na superfície desta, em uma quantidade de $190 \mathrm{mg}$, quantidade esta correspondente a $100 \mathrm{~kg}$ N/hectare. Para captar a amônia volatilizada colocou-se um disco de papel filtro em posição horizontal acima da terra, tratado com $1 \mathrm{~mL}$ de $\mathrm{H}_{2} \mathrm{SO}_{4}$ de concentração de $0,5 \mathrm{~mol} / \mathrm{L}$.

$\mathrm{O}$ ácido remanescente no coletor foi titulado com solução padronizada de $\mathrm{NaOH} 0,02$ $\mathrm{mol} / \mathrm{L}$. A análise foi realizada em estufa incubadora com temperatura controlada de $25^{\circ} \mathrm{C}$, por um período de 14 dias, sendo que os coletores foram trocados no primeiro, terceiro, sétimo e décimo quarto dias. Todas as amostras foram analisadas em tréplicas.

A quantidade de nitrogênio volatilizada sob a forma de $\mathrm{NH}_{3}$ em cada período foi calculada pela Equação 1.

$$
m g N-N H_{3 \text { volatilizado }}=\left(V^{\prime}-V^{*}\right) * 0,28
$$

em que $V^{\prime}$ é o volume de $\mathrm{NaOH} 0,02 \mathrm{~mol} / \mathrm{L}$ gasto na titulação do branco e $V^{*}$ é o volume de $\mathrm{NaOH} 0,02 \mathrm{~mol} / \mathrm{L}$ gasto na titulação do ácido remanescente nas parcelas do experimento. 

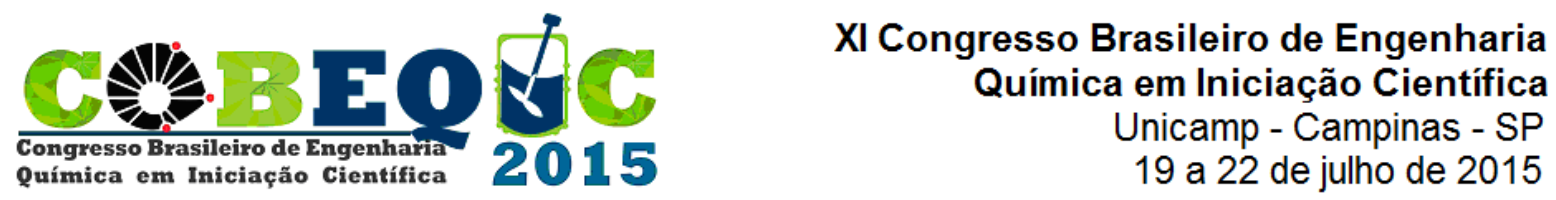

Também foram realizadas análises na uniformidade e regularidade da película formada sobre a partícula para as amostras dos quatro ensaios experimentais e a ureia sem recobrimento, utilizando um microscópio óptico com ampliação de $250 \mathrm{X}$.

\section{RESULTADOS E DISCUSSÃO}

Os resultados obtidos estão apresentados na Tabela 2, em que relaciona-se a quantidade de nitrogênio que foi liberada após um período de 14 dias para cada amostra, e o correspondente percentual de redução da volatilização da ureia recoberta em relação a não recoberta.

Tabela 2 - Nitrogênio liberado e percentual de redução.

\begin{tabular}{ccc}
\hline Ensaio & Total liberado $\left(\mathrm{mg} \mathrm{NH}_{3}\right)$ & \% de redução \\
\hline Sem recobrimento & 9,59 & - \\
1 & 7,89 & 17,80 \\
2 & 5,67 & 40,95 \\
3 & 5,69 & 40,66 \\
4 & 4,70 & 50,97 \\
\hline
\end{tabular}

Observa-se através da Tabela 2 que os filmes de recobrimento proporcionaram uma diminuição das perdas por volatilização de nitrogênio para todas as condições analisadas, em que o percentual de redução na volatilidade ficou entre de 17 e $50 \%$, sendo estes resultados satisfatórios. Os resultados indicam que os ensaios com vazão de suspensão e temperatura mais elevadas resultaram em partículas que proporcionaram maior redução da volatilidade.

A Figura 2 apresenta o perfil de liberação do nitrogênio volatilizado diário, durante um período de 14 dias para a ureia sem e com recobrimento.

Figura 2 - Perfil de liberação do nitrogênio volatilizado.

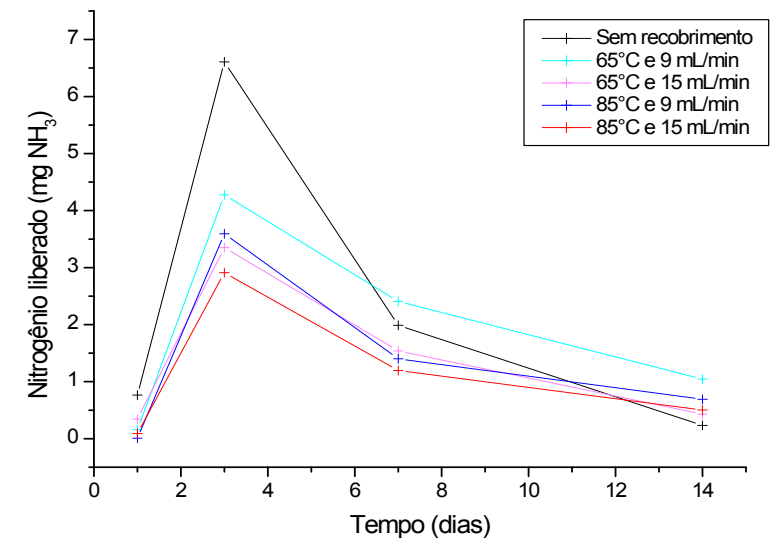

Pode-se observar na Figura 2 que a ureia sem recobrimento apresentou um pico correspondente a uma elevada quantidade de nitrogênio volatilizado no terceiro dia. Este comportamento foi observado com menos intensidade para a ureia recoberta, demonstrando 
que o filme de recobrimento foi efetivo no controle da liberação do nitrogênio contido no interior da partícula. Também verificou-se que o recobrimento que mais reduziu a volatilidade foi o recobrimento no ensaio a $85^{\circ} \mathrm{C}$ e $15 \mathrm{~mL} / \mathrm{min}$.

Estudos realizados por Costa et al., (2007) também verificaram que as perdas por volatilização do nitrogênio são maiores nos primeiros dias após sua aplicação, o que pode ser justificado pelo fato do solo elevar seu pH devido a hidrólise da ureia o que facilita as perdas de nitrogênio na forma de amônia.

As partículas de ureia foram analisadas antes e após o recobrimento quanto à uniformidade e regularidade da superfície dos grânulos em microscópio óptico. A Figura 5 apresenta as superfícies das partículas em microscópio óptico com ampliação de $250 \mathrm{X}$.

Figura 3- Micrografias da superfície das partículas de ureia antes e após o recobrimento, com ampliação de $250 \mathrm{X}$, inteiras e em corte transversal.

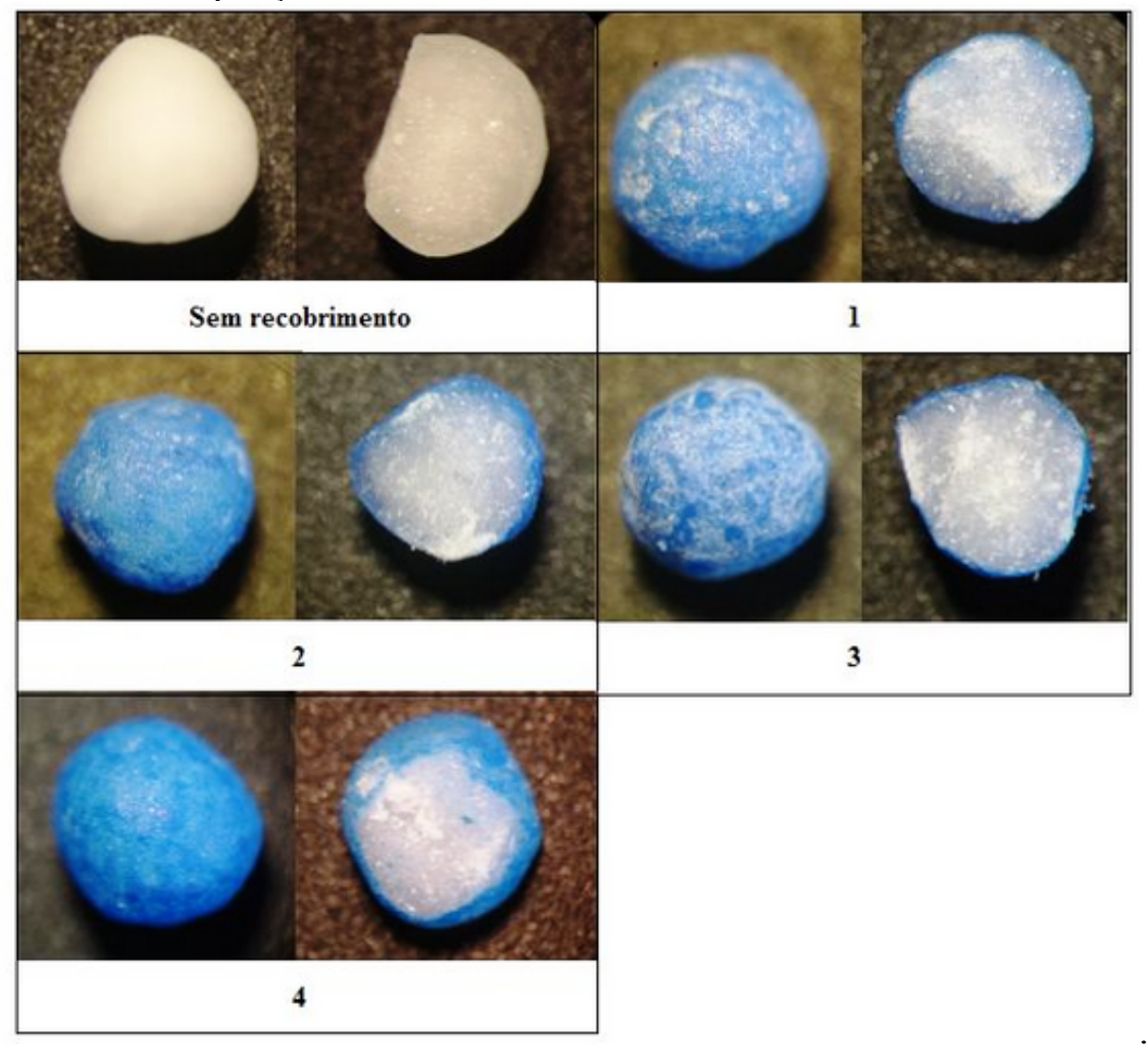

Pode-se verificar pela Figura 3 que os filmes de recobrimento envolveram as partículas conforme o esperado. Também foi verificado que a ureia sem recobrimento não apresenta uma superfície homogênea, contendo irregularidades. É possível constatar a presença de cristais em sua superfície, que são características típicas da sua estrutura cristalina (Vaughan e Donohue, 1952). As partículas de ureia recobertas nos ensaios 2 e 4 apresentaram uma superfície uniforme e homogênea, confirmando que o material de recobrimento teve um bom espalhamento e secagem na superfície das partículas. Já nas partículas resultantes dos ensaios 1 e 3 é possível verificar algumas imperfeições no filme, sendo que estas podem ser causadas 

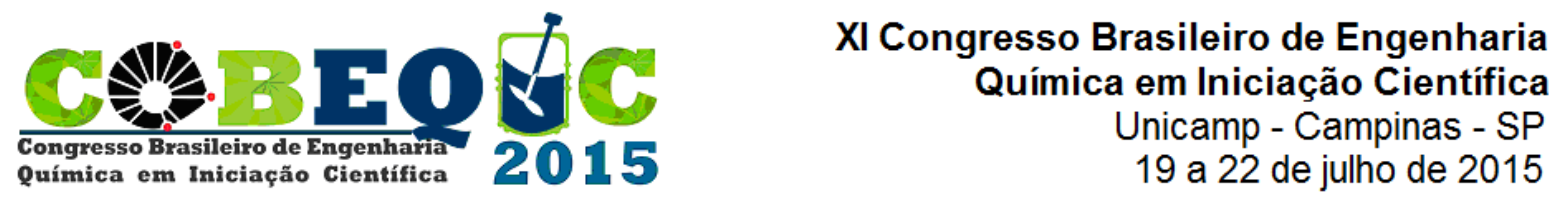

devido à baixa vazão de suspensão de recobrimento, o que dificulta a obtenção de um filme mais espesso.

\section{CONCLUSÃO}

Os filmes de recobrimento proporcionaram uma diminuição das perdas por volatilização de nitrogênio para todas as condições analisadas, em que o percentual de redução na volatilidade ficou entre de 17 e $50 \%$, sendo estes resultados bastante satisfatórios.

Através do perfil de liberação do nitrogênio verificou-se que a ureia sem recobrimento apresentou um pico correspondente a uma elevada quantidade de nitrogênio volatilizado no terceiro dia. Este comportamento foi observado com menos intensidade para as ureias recobertas, demonstrando que o filme de recobrimento foi efetivo no controle da liberação do nitrogênio contido no interior da partícula.

Também foi verificado através das análises de morfologia das superfícies que os recobrimentos com maiores vazões de suspensão formaram nas partículas um filme mais uniforme e homogêneo.

\section{REFERÊNCIAS BIBLIOGRÁFICAS}

COSTA, M. C. G.; VITTI, G. C.; CANTARELLA, H. Volatilização de N-NH3 de fontes nitrogenadas em cana-de-açúcar colhida sem despalha a fogo. Rev. Bras. Ciênc. Solo, Viçosa, v. 27, p. 631-637, 2003.

DUARTE, D. S. A. Perdas de amônia por volatilização em solo tratado com ureia, na presença de resíduos cultuais. Dissertação (Mestrado em Solos e Nutrição de Plantas) Escola Superior de Agricultura "Luiz de Queiroz", Universidade de São Paulo, Piracicaba, 2007.

LARA CABEZAS, W. A. R.; KORNDÖRFER, G. H.; MOTTA, S.A. (1997), "Volatilização de N-NH3 na cultura de milho: II. Avaliação de fontes sólidas e fluidas em sistema de plantio direto e convencional". Rev. Bras. Ciênc. Solo, Viçosa, v. 21, n. 3, p. 489- 496.

PADILHA, C. S. (2005), Uniformidade de aplicação de fertilizantes com diferentes características físicas. Relatório de estágio do curso de Agronomia. $83 \mathrm{f}$. Universidade Federal de Santa Catarina.

ROSA, G. S. Recobrimento de Ureia em Leito de Jorro para Minimizar as Perdas de Nitrogênio por Volatilização. Dissertação (Mestrado em Engenharia Química) Universidade Estadual de Campinas. Campinas, 2009.

VAUGHAN, P.; DONOHUE, J. The structure of urea. Interatomic distances and resonance in urea and related compounds. Acta Crystallography, Malden, v. 5, p. 530-535, 1952. 